\title{
Sacrifice is a step beyond convenience: A review of convenience sampling in psychological research in Africa
}

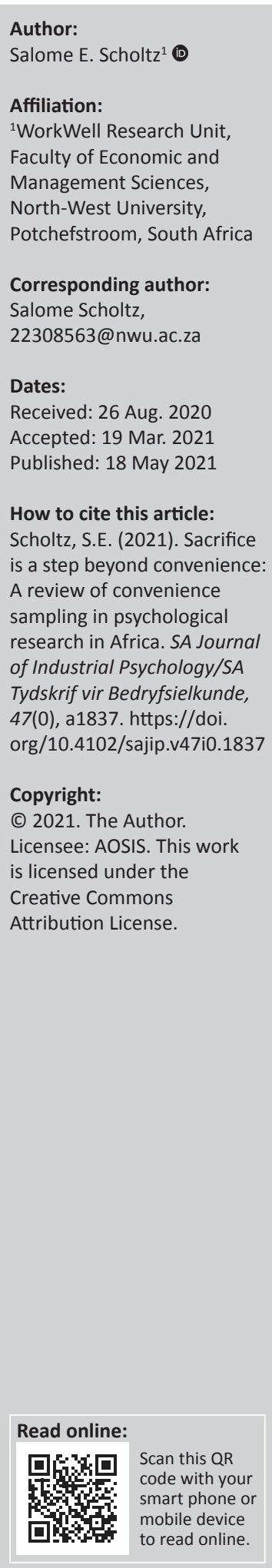

Orientation: Articles from three African psychology journals were reviewed to indicate their use and reporting practices of convenience samples.

Research purpose: Method-relevant sections of empirical research reports (qualitative, quantitative, mixed method, etc.) were categorised to establish current method use and reporting practices as well as the methodological standards of convenience sampling in three African psychology journals from 2018 to mid-2020.

Motivation for the study: Convenience sampling is the most popularly used sampling method in psychology. However, little attention is paid to sampling composition and sampling methods in articles, which influences trustworthiness, generalisability and replication of results. Psychology is also experiencing criticism because of the lack of non-Western, educated, industrialised, rich and democratic (WEIRD) samples.

Research approach/design and method: A systematised review design was followed to purposively collect and categorise articles that used convenience samples as a sampling approach $(n=139)$ from the South African Journal of Industrial Psychology, the South African Journal of Psychology and the Journal of Psychology in Africa.

Main findings: General reporting practices included sample size, gender, country, sample source (e.g. university) and age. Other sample characteristics indicate that studies were primarily conducted with South Africans speaking Afrikaans or English. English was mainly used to collect data from primarily black (African) and white (Caucasian) racial groups. Participants were largely female from university or college. Some sample differences such as sample size were also noted between qualitative and quantitative research methods. African journals' reporting practices of sample characteristics were found to include standards and frequencies similar to or higher than those of international journals.

Practical/managerial implications: Journals should pay attention to their role in influencing the reporting practices and standards of convenience samples and consider incorporating the presented categories.

Contribution/value-add: The use of convenience sampling in African psychology journals is presented along with the potential of African research to provide non-WEIRD samples in psychology. Recommendations for improving the use of this sampling method are highlighted.

Keywords: Africa; convenience sampling; external validity; psychology; research methodology; sampling; sample diversity; WEIRD samples.

\section{Introduction}

\section{Orientation}

Probability and non-probability sampling methods are used by researchers to learn about a population (Maree \& Pietersen, 2016). The adequacy of these samples is determined by the composition, size (Vasileiou et al., 2018) and the chosen sample's representativeness (Hanges \& Wang, 2012). Despite being at the heart of research, psychology still pays little attention to sampling methodology (Fisher \& Sandell, 2015; Robinson, 2014). Scholtz, De Klerk and De Beer (2020) found a lack of transparency in top-tier miscellaneous international psychology journals regarding the sampling methods. This lack of transparency was evident in articles regardless of the applied research method (e.g. qualitative and quantitative research methods). Furthermore, the justification for using specific sampling techniques is rare in industrial and organisational 
psychology (I-O psychology) research and related textbooks (Landers \& Behrend, 2015). Consequently, the pros and cons of the used samples are rarely stated or paid attention to, despite calls for more details on the context of samples (Rynes, 2012). According to Rad, Martingano and Ginges (2018), psychology studies should include at least the socioeconomic status (SES), ethnicity, age, religion, nationality and gender breakdown of samples. Sample response rates are also too often missing in articles which inhibit readers from assessing the quality of the sampling used in studies (Fisher \& Sandell, 2015). However, Zhao (2020) encourages balance in what is stated in articles and requested from participants to make stating sampling characteristics in articles feasible and uphold the confidentiality and validity of the included sample. The lack of sample details and precision in sampling debilitates the science of psychology by hampering replication (Trafimow, 2018), which is impossible if study samples do not concur (Simons, Yuichi, \& Lindsay, 2017; Stroebe, Gadenne, \& Nijstad, 2018), thereby furthering the current replication crisis faced by the field (Open Science Collaboration, 2015).

\section{Literature review}

The most popularly used sampling method in psychology is convenience sampling, a non-probability sampling method (Hultsch, MacDonald, Hunter, Maitland, \& Dixon, 2002; Zhao, 2020). Convenience sampling collects data from whoever is willing to partake in a study, is the most approachable or is, in other ways, conveniently accessible to the researcher (Wienclaw, 2019). These samples often consist of much-debated student samples (Ashraf \& Merunka, 2017; Zhao, 2020) or organisation's researchers have a relationship with or any persons who are willing to complete their surveys (Landers \& Behrend, 2015). The popular use of easily accessible samples may be a result of the publish or perish culture in academia. Researchers often scramble to publish whatever they can to stay employed rather than taking the time to create significant research or teach students (Rawat \& Meena, 2014). Convenience sampling poses various limitations to research in the field of psychology. Robinson (2014) indicates that sampling can influence qualitative data's validity, whilst peer reviewers also often criticise research articles for using convenience samples (Landers \& Behrend, 2015). Convenience samples are also not necessarily representative of the population the research is based on (Staetsky, 2019), which severely hampers generalisability. For example, results from one organisation may not represent other organisations in the same sector as each organisation has applied selection criteria to their employees for employment which differentiates its population from other organisations (Landers \& Behrend, 2015). Generalisability is seen as a critical aspect that makes studies original and leads to reviewers in psychology accepting manuscripts, whereas inappropriate sampling often leads to rejection (Fonseca, 2013).

To further complicate research for non-western populations, such as Africa, research samples in psychology are mostly western, educated, industrialised, rich and democratic (WEIRD) (Henrich, Heine, \& Norenzayan, 2010), with minimal attempts in practice to increase diversity (Medin, Ojalehto, Marin, \& Bang, 2017). Thus, the largest part of the world's population is underrepresented in psychology fields such as developmental psychology (Nielsen, Haun, Kärtner, \& Legare, 2017), with most studies consisting of Euro-American samples (Zhao, 2020). Rad et al. (2018) also found that in a high-impact international psychology journal only six articles were published with African samples in 2014 and none in 2017. This underrepresentation places Africa, the fastest-growing population in the world (United Nations, 2019), in a position to contribute unique research to the field of psychology, especially as cultural differences have been found to influence the research results of psychology (Mesoudi, 2011). Africa consists of 54 countries, each with its own set of cultures and ethnicities that influence behaviours, beliefs, languages and values, distinguishing the population from the rest of the world (Idang, 2015).

The lack of attention paid to sampling in psychology can be because of various reasons. For example, other sampling methods, such as specific probability methods (e.g. stratified sampling), are reportedly more expensive than convenience samples (Acharya, Prakash, Pikee, \& Nigam, 2013; Jager, Putnick, \& Bornstein, 2017; Kakinami \& Connor, 2010). Steckler and McLeroy (2008) also indicate researchers, funders and journals believed scientific rigour (internal validity) to be more critical than the generalisability of results (external validity) throughout history. Jimenez-Buedo and Miller (2010) highlight the debate and the trade-offs between internal and external validity in social research, which is also reiterated by Landers and Behrend (2015). Researchers often focus large sections of their reports on describing internal validity (e.g. measure identification); however, external validity is confined to a short statement in the limitation section (Landers \& Behrend, 2015). Moreover, psychology programmes and peer reviewing also show little interest in external validity (Fisher \& Sandell, 2015). Research method training in general of undergraduate and graduate students has long been a concern for social research. Researchers often have trouble teaching and learning various research methodologies because of a lack of confidence and method expertise (Buckley, Brown, Thomson, Olsen, \& Carter, 2015; Hesse-Biber, 2015; Scott Jones \& Goldring, 2015). The I-O psychologists specifically are called to pay more attention to research method education and especially sampling in graduate courses (Fisher \& Sandell, 2015). Landers and Behrend (2015) add that coverage of external validity is limited in research education and research textbooks. This lack of interest has further limited literature on external validity as well as the application of research findings to practice (Steckler \& McLeroy, 2008) which has become a worldwide phenomenon (Pietersen, 2018).

Collecting data from convenience samples is limited for various reasons, for example results can hold strong hidden biases (Palinkas, Horwitz, Green, \& Wisdom, 2013) and can only be generalised to those individuals in the population 
who bare the same characteristics as the sampled group (Andrade, 2020). Additionally, samples can include outliers or persons who feel they belong to the specific study (Etikan, Musa, \& Alkassim, 2016). Thus, Steckler and McLeroy (2008) highlight the importance of strengthening and emphasising external validity. To counter the impact of convenience sampling on external validity, Simons et al. (2017) proposed using the constrains on generality (COG) statement where psychologists insert specifications on the intended target population and its representation in their studies. It has become common practice in psychology to include statements that identify the sampling method as a study limitation in articles (Landers \& Behrend, 2015; Simons et al., 2017). However, Barratt, Ferris and Lenton (2015) found that researchers and readers may eventually extrapolate findings beyond non-probability samples, despite the authors indicating it as a limitation and thereby causing a 'lumpy social world' (Lucas, 2014, p. 391). Landers and Behrend (2015) also add that the I-O psychology researchers still often make or suggest broad generalisations based on their findings, even with their sampling listed as an explicit limitation. More recently, Rad et al. (2018) found that mostly cross-cultural and developmental psychology studies reported their results in the context of their sampled population whilst the remainder of studies tends to make broad general conclusions from their findings based on western samples.

Other previous research on sampling in psychology includes Pollet and Saxton (2019). Their investigation into sample composition in two international evolutionary psychology journals showed that despite samples being more diverse than those found in developmental and social psychology, only six articles of the 311 collected drew samples from African countries. A review of the highest impact factor experimental psychology journals provided similar results (Nielsen et al., 2017). Aguinis and Solarino (2019) reviewed the qualitative I-O psychology studies published in the Strategic Management Journal and found no clear sampling procedures. In South Africa, Coetzee and Van Zyl (2014) reported sample size trends of 501-1000 participants between 2004 and 2013 in the South African Journal of Industrial Psychology (SAJIP). Inadequate sampling has also been noted as a reason for rejecting manuscripts for SAJIP (Coetzee \& Van Zyl, 2013). Visser and Van Staden (1990) reviewed the sampling method used in SAJIP from 1979 to 1988 and found that only $3 \%$ of the samples was described, 53\% used non-random sampling whilst $25 \%$ of the articles indicated no sampling strategy. Except for Visser and Van Staden's 1990 review of a South African journal, reviews of sampling methods used in psychology in Africa are lacking (see O’Neil \& Koekemoer, 2016; Pietersen, 2018; Schreuder \& Coetzee, 2010).

\section{Research purpose and objectives}

From the literature, it is clear that psychologists face a dilemma regarding convenience sampling, as they may have just cause to use this sampling method (see Wienclaw, 2019) but are faced with various caveats in its use and reporting.
For this reason, Fisher and Sandell (2015) called for the next generation of psychology researchers to pay more attention to the use of methodology and sampling composition. They encourage clear sampling frames, proper justification of the included sample regarding the target population and evidence of sampling error. Scaring researchers away from convenience samples can slow the progress made in psychology fields (Landers \& Behrend, 2015). Therefore, researchers are instead encouraged to carefully consider their use of convenience samples in various psychology areas and the impact of drawing from different convenience sampling sources (Landers \& Behrend, 2015). For example, Jager et al. (2017) advocate homogenous convenience samples as a way to overcome the limitations of convenience sampling in the field of developmental psychology. Landers and Behrend (2015) and McEwan (2020), on the other hand, encourage researchers to evaluate their external validity by asking themselves whether the range restrictions imposed by convenience sampling correlate with the interested variables. Lastly, Staetsky (2019) adds that samples of convenience are appropriate if research consumers are informed of their precision, the limitations are made apparent and it exists as a part of other statistical products. Thus, because of the the lack of attention paid to sampling in psychology overall (Fisher \& Sandell, 2015; Robinson, 2014) and the African context specifically as well as the lack of non-WEIRD samples in psychology research (Medin et al., 2017), this study aimed to review the use and reporting of convenience sampling in African psychology journals. This study, therefore, sought to add insight into the use of convenience sampling to recommend a productive way forward for psychology in Africa through a review of the literature.

With the accelerated growth and vast amount of available research, literature review methods have become more relevant than ever (Snyder, 2019). The synthesis of empirical studies addresses research questions with more power than a single study and possibly over various disciplines (Snyder, 2019). Additionally, Shen et al. (2011) state that to promote growth and change in a field, taking stock of current practices through reviews is required. This review could, therefore, firstly highlight the use and reporting of convenience sampling in psychology from a broad base of literature. Secondly, areas of growth for reporting convenience sampling or gaps for improving study rigour could be identified for researchers, reviewers and journals in African psychology research. Thirdly, sampling demographics will also become apparent to indicate the breadth of the included samples as literature shows international research typically included WEIRD samples above others (Landers \& Behrend, 2015). Similarly, Stroebe et al. (2018) state that the lack of diversity in study samples have become a growing concern in psychology overall. Thus, studies on sample diversity could provide valuable information for improving research and formulating applicable interventions in a diverse continent such as Africa. Fourthly, Gentles, Charles, Nicholas, Ploeg and McKibbon (2016) also identified the formulation of new guidelines as a possible outcome of reviews. Lastly, this study initiates a dialogue about convenience sampling specifically 
and its application in the African context, contributing to the literature in psychology overall.

This study's general objective is to survey the sections concerned with sampling methodology in empirical studies (e.g. qualitative, quantitative, mixed-method research design, etc.) to determine the current use and reporting practices of convenience sampling in African psychology journals. This objective concurs with that indicated by Gentles et al. (2016) for methodological reviews. The research question was What are the current use and reporting practices of convenience sampling in African psychology journals?

Based on the posed research question and general objective, the following specific objectives were explored:

- Categorise method-relevant sections of empirical research reports to establish the use of current convenience sampling method and reporting practices in African psychology journals.

- Establish the methodological standards of convenience sampling in African psychology journals.

\section{Research design}

\section{Review approach}

A systematised review design was followed for this study. Systematised review designs include elements of a systematic review, such as a comprehensive search or quality assessment (Grant \& Booth, 2009). Grant and Booth (2009) expand on this review design describing it as a search of one or two databases to catalogue literature from a comprehensive search in tabular form.

\section{Sample}

Purposeful sampling was used to select journals for this review. Purposeful sampling refers to the most effective use of limited resources by selecting information-rich cases (Patton, 2002) for the aim of a study. Per the aim of this study, 139 articles were chosen based on the following inclusion criteria: Firstly, only African academic journals concerned with psychology listed on the Web of Science Master Journal list (Web of Science Group, 2020) were selected. Gentles et al. (2016) identified journals as the most likely resource for methodology reviews in practice. Thus, the following journals were included: South African Journal of Psychology (SAJP), SAJIP and the Journal of Psychology in Africa (JPA). Secondly, articles published from 2018 to mid-2020 were selected. Two most recent years is an appropriate time frame as suggested by Gentles et al. (2016) for reviews aimed to show how the concept of a method is currently operationalised and reported by authors in research. Opinion pieces, reviews, discussion and theoretical pieces were excluded as these papers do not include the methodological aspect under investigation.

\section{Research procedure}

The research procedure followed in this study was adapted from that followed in Scholtz et al. (2020) and is indicated in
Appendix 1, Figure 1-A1. After receiving ethical approval, the researcher applied the inclusion and exclusion criteria to the identified journals to include and exclude relevant articles. A total of 361 empirical articles were read, and only 139 were identified as using convenience sampling. The researcher documented reasons for inclusion and exclusion and the included articles were logged in EndNote.

The essential principles designed by Gentles et al. (2016) for conducting systematic reviews of methods was included and adapted for this systematised review (Grant \& Booth, 2009). However, these principles were adjusted following the aim of this systematised review design, namely, literature selection and data extraction (Johnston, Kelly, Hsieh, Skidmore, \& Wells, 2019). In principle 1, researchers indicated the boundaries of appropriate method-relevant literature for the study objective. Explicit inclusion and exclusion criteria were provided that focused on method's literature (convenience sampling) in the identified South African journals (Gentles et al., 2016). Principles 2 and 3 referred to the inclusion of other resources that do not align with the aim of this systematised review design. Principle 4 suggested that the reviewers consider the spectrum of 'purposeful literature sampling approaches at their disposal in deciding what best matches the specific aims of their own reviews' (Gentles et al., 2016, p. 6). To address this principle, a purposive sampling method was followed. Principle 5 is concerned with the rigorous extraction of data. Therefore, the current review followed the identified data abstraction form (Table 1) in abstracting data related to the research objectives (Gentles et al., 2016). In principle 6, the researchers were cognisant that concept wording might differ in publications. Thus, when extracting data, the researcher relied on definitions of the relevant concepts (e.g. convenience sampling) instead of only wording.

An abstraction form that consisted of article identifiers and all information listed in Tables 1-4 was used to extract data and create themes for using and reporting convenience sampling in the selected African journals. This form was iteratively revised and based on the literature and the identified objectives to ensure rigorous data abstraction (Gentles et al., 2016). A second reviewer, a registered industrial and research psychologist reviewed the included sample and the derived themes. Disagreements were highlighted and discussed with the researcher, and any changes were documented. Data analyses focused on the methods-relevant section, as indicated by Gentles et al. (2016), to review methods. However, the articles' full text was also read to ensure all relevant data were included. Additionally, as Landers and Behrend (2015) highlight researchers' common practice to discuss the limitations of convenience samples in the limitation sections of articles, these sections were also of concern during data abstraction. Thematic data analysis was followed in this study to systematically organise and identify patterns and broad themes from data that form part of the abstraction form (Braun \& Clark, 2012). The following phases of thematic analysis were followed: In phase one, the researcher 
familiarised herself with the data by reading and re-reading the selected articles. During phase two, initial codes were generated by labelling data extracts that can potentially address the research question. In the third phase, the codes were used to create patterns or themes. Phase four focused on reviewing the identified themes and their relation to the data. After reviewing the themes, the theme names were derived in phase five, and lastly, phase six focused on writing a report.

Regarding the final principle (7), Gentles et al. (2016) suggest a data extraction method should be comparable with the outcome or final product of the review. A systematic review means that the extraction of literature should allow for a qualitative description and interpretation of results. The systematised design requires results to narratively be tabulated and described; thus, a tabular extraction was used to create Tables 1-4. Upon agreement of the final results, the researcher wrote a report presenting the results, per the systematised review design (Grant \& Booth, 2009).

\section{Ethical considerations}

Ethics clearance for this study was obtained on 17 August 2020, with ethics number: NWU-00760-20-A4 from the North-West University, Potchefstroom. No participants were included in this study, and all data used were collected in a transparent manner from publicly available resources.

\section{Results}

Results for this study are presented in Tables 1-4. Table 1. shows the distribution of the included articles $(n=139)$ from the selected journals.

The Journal of Psychology in Africa contributed to the highest frequency of articles utilising convenience sampling. However, SAJIP was the journal with the highest frequency of articles that clearly identified the used sampling method as convenience sampling (93\%). Whereas JPA identified $72 \%$, SAJP stated the use of convenience sampling in $54 \%$ of the studies. Articles were also included based on having characteristics of the convenience sampling method. Additionally, of the 139 articles, 9 articles used convenience sampling in conjunction with other non-probability sampling

TABLE 1: Frequency of convenience sampling in African psychology journals.

\begin{tabular}{lcc}
\hline Journal & $\boldsymbol{f}$ & Reported \\
\hline Journal of Psychology in Africa (JPA) & 87 & 63 \\
South African Journal of Industrial Psychology (SAJIP) & 30 & 28 \\
South African Journal of Psychology (SAJP) & 22 & 12 \\
\hline
\end{tabular}

$f$, frequency.

TABLE 2: Frequency of convenience sampling in method use.

\begin{tabular}{lcc}
\hline Method & $f$ & Reported \\
\hline Quantitative & 109 & 80 \\
Qualitative & 26 & 20 \\
Combined & 2 & 1 \\
Mixed & 2 & 2 \\
\hline
\end{tabular}

$f$, frequency. methods to select sample regions or participants. For example, Hlatshwayo, Muthukrishna and Martin (2018) used purposive sampling, and Van Leeuwen et al. (2018) added snowball sampling and their convenience sample.

To further show the current reporting and use of convenience sampling, the following categories were created and tabularised: Firstly, the frequency of convenience sampling was created with regard to the research methods (Table 2), which shows that quantitative methods, the most frequently used research method in this sample, clearly stated its use of convenience sampling in $73 \%$ of its articles of which $60 \%$ of these articles were from JPA. Of the two highest occurring methods (quantitative and qualitative research methods), the following sample reporting differences were observed: $12 \%$ of the quantitative articles reported sample strengths and weaknesses compared to $0 \%$ of the qualitative articles. Only $15 \%$ of qualitative articles reported the sample age mean compared to $49 \%$ of quantitative articles. Quantitative studies were also more prone to report the employment (64\%) and education $(67 \%)$ of the participants compared to qualitative studies (58\% and 46\%). However, qualitative studies collected data in participants' own language (19\%) and indicated the SES $(15 \%)$ of participants in more articles than quantitative studies $(6 \%$ and $9 \%)$.

Secondly, the characteristics of the convenience sampling method, specifically, as reported by authors, were categorised in Table 3.

Sample sizes were reported by all included articles, whereas justification for the selected sample was limited. Sample justification referred to any justification authors provided for selecting specific participants or sample sizes. For example, Osei-Tutu, Dzokoto, Hanke, Adams and Belgrave (2018) provided the following rationale that concurred with their study aim:

We chose to interview Christians because this is the religion of the majority of Ghanaians and also because of the significance of the concept of love within the Christian faith. (p. 84)

Additionally, Henn and Morgan (2019) explained using more than one sampling method and why random sampling in the context of the chosen population was not possible.

Sample strengths and weaknesses (outside of sample generalisability) were also stated in a limited number of

TABLE 3: Reported convenience sampling method characteristics.

\begin{tabular}{lc}
\hline Sampling method characteristics & $\boldsymbol{f}$ \\
\hline Size reported & 139 \\
Sample justification & 21 \\
Sample strengths or weaknesses & 14 \\
Sample response rate & 22 \\
Generalisability & 94 \\
Representativeness & 33 \\
Information of influence of sample on results & 51 \\
Limitation statement (sample size) & 50 \\
Limitation statement (convenience sampling method) & 43 \\
Encourage future sampling from different contexts & 78 \\
\hline
\end{tabular}

$f$, frequency. 
studies. For example, Redelinghuys et al. (2019) stated that the cross-sectional design was a weakness of their study as it 'impedes the assessment of causality among the variables under scrutiny' (p. 11).

Generalisability and replication were also added as categories to indicate the reported generalisability of results and whether samples were reported as representative of their study population. As shown in Table 3, more studies included statements on the generalisability of their results than their representativeness. These types of accounts were often under the limitation and recommendation sections of articles. Keyser and Duvenhage (2019) present an example of this statement: 'Limitations of this study include that the sample was drawn from among university students rather than the general population. This limits the generalisability of findings' (p. 463).

In addition to the generalisability of samples, some researchers also provided information on their sample's possible influence on their study results. Kagee, Bantjes, Saal and Sefatsa (2019), for example, state that because of the selfselection nature of their study, participants who experienced emotional distress might have been more prone to enrol for data collection than those who did not, in their study of posttraumatic stress disorder (PTSD) related to HIV testing.

Articles using convenience sampling also provided limitation statements regarding the sample size, such as Van Leeuwen et al. (2018) or Potgieter and Ferriera (2018). Additionally, of the included sample, $31 \%$ provided a statement indicating the sampling method as a limitation. For example, a 'limitation of the study was the use of the convenience sampling approach' (Maximo, Stander, \& Coxen, 2019, p. 11). Researchers recommended future research from larger samples or samples from different contexts (Renard \& Snelgar, 2018) in 56\% of articles. Certain studies also called for replication of their research using different samples. For example, Shoko (2019) calls for replication in various Zimbabwean communities.

In addition to the reported characteristics regarding the sampling method, the authors also provided various details regarding the sampled participants (Table 4 ).

The mean sample size of the included articles was 319 (SD $=424.1)$, with the largest sample $(n=3912)$ by Morton, Hill, Meiring and De Beer (2019). The smallest sample $(n=3)$ was by Mngomezulu (2019). The modus samples were: 300, 201, 7 (3 studies) and 8 participants (4 studies). The mean sample size for qualitative studies was 31 participants (female and male) and 390 participants for quantitative studies. The total samples of all articles combined (that indicated gender) showed female $(65 \%)$ comprised majority of participants. Overall convenience samples for qualitative studies indentified $64 \%$ female and $32 \%$ male participants, whereas quantitative studies reported $54 \%$ female and $43 \%$ male participants. Results also showed that $3 \%$ of the included participants' gender was not indicated in studies.
Age was omitted entirely in 14 articles whilst 30 articles also did not provide an age range, only the sample mean age was provided.

Sample racial composition was stated in $58 \%$ of the sampled articles. Most studies referred to the sample race (e.g. black people, white people, Indian, etc.), with a select few authors providing more details regarding participants' ethnicity. Anyaegbunam and Anazonwu (2018), for example, specified the ethnic origin of participants as Igbo, Yoruba, Hausa or Fulani and others. Additionally, this review found that some studies only indicated the racial group that made up most of the sample. For example, Gani, Potgieter and Coetzee (2020) stated their sample was 'predominantly black (57\%)' (p. 145) and Potgieter and Ferreira (2018) included a sample of 'predominantly mixed-race' participants (p. 401).

The home language was reported in $31 \%$ of the sample and included various languages per article. Arendse and Maree (2019) had all South African languages, whereas Kagee et al. (2019) excluded persons who understood no English. The highest frequency home languages for participants in the sampled journals were Afrikaans and English. However, the language that data were collected in was often omitted by authors, with 12 studies reporting to collect data in the participants' home language and 32 in English (Geils \& Edwards, 2018). It is important to note that certain studies collected data in English and other languages such as Kiswahili (Ndungu, Ndetei, Cronje, \& Van Rooyen, 2018) or SiSwati (Ntinda \& Dlamini, 2019).

Occupation and education were indicated equally frequent in the sample, with little reporting on the SES of participants. A select few articles stated the lack of these characteristics as a limitation, for example Dankaert, Guse and Van Zyl (2019) lists the lack of SES in their study as a limitation and the possible influencing factor regarding their results. The samples were mainly drawn from South Africa, with JPA providing the most sample country diversity. Further details regarding the sample source and participant characteristics were reported, whereas many used university, organisations or specific country regions and provided details regarding marital status and family structures.

\section{Discussion Outline of results}

This study reviewed and categorised the current use and reporting practices around convenience samples in African psychology journals. Overall results show that authors frequently used convenience sampling in the included articles, concurring with Hultsch et al. (2002) and Zhao (2020) as the popular sampling method in psychology. It also seemed that journals listing sampling method as a requirement in manuscripts increased the used sampling method's reporting, highlighting the influence journals have on sample reporting practices. For example, reporting the sampling method is a requirement for SAJIP manuscripts 
TABLE 4: Convenience sample participants' characteristics.

\begin{tabular}{|c|c|}
\hline Sample characteristic & Total participants $f=44678$ \\
\hline \multicolumn{2}{|l|}{ Gender $(n=135)$} \\
\hline Male & 19307 \\
\hline Female & 24093 \\
\hline \multicolumn{2}{|l|}{ Age $(n=109)$} \\
\hline Age mean reported & 59 \\
\hline Oldest participant & 75 \\
\hline Youngest participant & 8 \\
\hline \multicolumn{2}{|l|}{ Race $(n=80)$} \\
\hline Black (African) people & 66 \\
\hline White (Caucasian) people & 47 \\
\hline Mixed-race (coloured) people & 33 \\
\hline Indians & 23 \\
\hline Asians & 17 \\
\hline Others & 11 \\
\hline Missing & 3 \\
\hline \multicolumn{2}{|l|}{ Language $(n=43)$} \\
\hline Data collected in own language & 12 \\
\hline Data collected in English & 32 \\
\hline \multicolumn{2}{|l|}{ Sample home language } \\
\hline Afrikaans & 23 \\
\hline English & 19 \\
\hline IsiZulu & 9 \\
\hline Sesotho & 8 \\
\hline Setswana & 8 \\
\hline African or Indigenous & 7 \\
\hline IsiXhosa & 6 \\
\hline Sepedi & 5 \\
\hline SiSwati & 3 \\
\hline French & 3 \\
\hline Tshivenda & 3 \\
\hline Chinese & 3 \\
\hline Xitsonga & 2 \\
\hline Others & 2 \\
\hline All South African languages & 2 \\
\hline Kiswahili & 1 \\
\hline IsiNdebele & 1 \\
\hline Dutch & 1 \\
\hline Korean & 1 \\
\hline Indonesian & 1 \\
\hline Cambodian & 1 \\
\hline Vietnamese & 1 \\
\hline Occupation or employment & 87 \\
\hline Education & 87 \\
\hline Socio-economic status & 14 \\
\hline \multicolumn{2}{|l|}{ Country ( $n=139)$} \\
\hline South Africa & 103 \\
\hline Nigeria & 11 \\
\hline Ghana & 8 \\
\hline China & 5 \\
\hline United States of America & 4 \\
\hline Zimbabwe & 4 \\
\hline Democratic Republic of the Congo & 3 \\
\hline Korea & 2 \\
\hline Uganda & 2 \\
\hline Belgium & 1 \\
\hline Eswatini (Swaziland) & 1 \\
\hline Kenya & 1 \\
\hline Namibia & 1 \\
\hline North America & 1 \\
\hline Australia & 1 \\
\hline Cambodia & 1 \\
\hline
\end{tabular}

TABLE 4 (Continues...): Convenience sample participants' characteristics.

\begin{tabular}{lc}
\hline \multicolumn{1}{c}{ Sample characteristic } & Total participants $\boldsymbol{f}=\mathbf{4 4 6 7 8}$ \\
\hline Philippines & 1 \\
Vietnam & 1 \\
United Kingdom & 1 \\
West Africa & 1 \\
Indonesia & 1 \\
Source detail ( $\boldsymbol{n}=\mathbf{1 3 5 )}$ & \\
University or college & 43 \\
Region or urban or rural areas & 32 \\
Organisation & 32 \\
Hospital or treatment centre & 12 \\
School & 12 \\
Festival or museum & 3 \\
Governmental institute & 3 \\
Jail & 2 \\
Online & 2 \\
Village & 2 \\
Venue & 1 \\
Attendance register & 1 \\
Orphanage & 1
\end{tabular}

Orphanage

Other characteristics $(n=57)$

Marital status

20

Family structure or relationships

Religion

Health status

characteristics

Disability

Crime perpetration or victim

Disadvantaged groups

Culture

Military service $\quad 2$

Region where person grew up

Bike make

English reading $\quad 1$

Housing

Note: The 'articles reported frequency' might not concur with the 'total frequency' of the categories as articles listed more than one (e.g. two or more countries for sampling) of the included characteristics.

$f$ frequency; $n$, total of articles that reported participant characteristic.

(AOSIS, 2020), whereas JPA indicates that participants should be included in the abstract and SAJP only provides general guidelines for article formatting (SAGE Publishing, 2021; Taylor and Francis Online, 2021). Further research on the impact of journal guideline on method reporting is, therefore, encouraged. The research method was also found to influence some sampling reporting. Convenience samples are often used because of the aim of quantitative studies to reach a certain breadth of understanding (Etikan et al., 2016). The frequency of qualitative methods that utilised convenience sampling was interesting as this research method tends to use purposive sampling to identify information-rich cases (Cleary, Horsfall, \& Hayter, 2014). Sample reporting practices could also be seen as indicative of article aims. For example, quantitative methods were used to pursue aims wherein occupation and education were of importance such as in the case of I-O psychology studies. The comparison sampling in qualitative studies showed the importance of collecting data in the participant's own language. However, as this study focused on convenience sampling in psychology articles regardless of the applied 
research method, further research is needed that selects research methods specifically from the sampled journals to determine their use of sampling confidently.

The study results further indicated the following general reporting practices of the sampled African journals (based on frequencies): sample size, gender, country, sample source (e.g. university) and in lesser amount age. The highest frequency reporting categories only include some of the minimum standards recommended by Rad et al. (2018), such as sample characteristics, the link between the findings and the population, justification for the chosen sample, generalisability of the findings and the impact of sample diversity on findings. This is in line with the previous research of international sampling trends, whereas most articles report the gender composition of samples (Rad et al., 2018). Furthermore, almost equal frequencies of articles were found to provide information on sample ethnicity, education and SES in this international journal and the current African sample, highlighting the applicability of the sampling recommendations made by Rad et al. (2018) for the included journals.

However, despite these similarities, the African journals also provided information on sample characteristics rarely stated by international journals, such as participant countries and sample sources (Rad et al., 2018). Additionally, listing the racial composition in $58 \%$ of articles and a few studies indicating participants' ethnicity make these African journals stand out against research submitted to international psychology journals (Rad et al., 2018; Rozin, 2001). Most of the samples also included black (African) people samples, which contrasts with the previous and international research. Visser and Van Staden's (1990) first study found intra-culturally oriented articles $(n=83 \%)$ consisted of nearly $50 \%$ of only white people samples in SAJP. This result also addresses the lack of diversity in the overall psychology samples. In contrast, Pollet and Saxton's (2019) review found $81 \%$ of articles in Evolutionary Psychology and Evolution and Human Behavior published between 2015 and 2016 still only included western samples. In their 2019 article, Pollet and Saxton highlighted that most researchers are WEIRD, and thus samples are more conveniently gathered from the same WEIRD population because of the ease of access compared to difficulties in collecting data from other countries. This sampling of WEIRD populations may be an essential aspect to consider regarding the current study results and a possible avenue for future research. Recommendations for future research regarding sampling (e.g. different sample size or composition) were also found to be made in more than half of the included articles, which is more than three times the number found by Rad et al. (2018) for international journals.

These reporting practices are commendable but improvement is still needed, which is apparent considering the low frequencies for some categories as shown in Tables 3 and 4 . A clear example of this need is the limited number of studies indicating the language of data collection. Roughly $70 \%$ of Africa has basic English literacy levels lagging behind the world average of $90 \%$ (Tasamba, 2019). The possible influence of literacy on study outcomes is, therefore, concerning. According to Vasileiou et al. (2018), research quality and trustworthiness are improved by the transparency of sampling methods. Transparency regarding the selection of participants as well as their characteristics is also integral for replication. Replication was recommended by various articles in the included sample (e.g. Waglay, Becker, \& Du Plessis, 2020), and this requires a sample that is comparable with the original study (Westfall, Judd, \& Kenny, 2015). Therefore, the improvement of reporting practices for convenience sampling is imperative not only for the trustworthiness of African research but also for making replication possible.

\section{Practical implications}

The current study provides a base for dialogue regarding convenience sampling in African psychology research. The practical implications suggested by the results are that journals should be cognisant of their role in reporting convenience samples. Thus, journals could use the results and categories of this study to create reasonable criteria for authors when submitting their manuscripts to improve sampling descriptions and transparency. This criterion is especially applicable regarding non-WEIRD samples as the results show African research can provide the much-needed research from the perspective of these groups. Therefore, rigour in describing these non-WEIRD characteristics is imperative to address the research gap and promote possibilities for replication studies.

\section{Limitations and recommendations}

The first limitation is that of the selected journal sample. The sample consisted of only three journals, of which two were drawn from the same country, which influenced the number of articles published in the South African context. However, these journals were still appropriate as they are accredited and more likely to be the journals used to contribute to the global knowledge economy. Therefore, it is important to highlight areas for methodological improvement to enhance the trustworthiness of African research internationally and increase psychology content from more diverse samples. However, future studies should still aim to include other African psychology journals, such as the African Journal for the Psychological Studies of Social Issues. Secondly, the sampling method categorisation was based on the inclusion of articles that provided convenience sampling method characteristics and authors' reporting of the used sampling method. Thus, the possibility exists that some articles might have been missed for inclusion if authors did not provide enough information for reviewers to identify articles as using convenience sampling. The use of a second reviewer aimed to limit this possibility. Thirdly, despite the results' concurrence with similar international studies, results should be interpreted in the context of the three included journals. 
The current study calls for more justification and transparency when using convenience sampling to improve replication opportunities of studies and the trustworthiness of results. Future articles concerned with sampling and its impact on knowledge generation is encouraged to inform research practice and education. This study provides a superficial view of convenience sampling and its relation to research methods. Further investigation into the use of sampling for specific research methods is, therefore, recommended. In addition to this study's objective, the results also provided content regarding the type of participants sampled in Africa, which can be used for further investigation. The current sample, for example, only included research on $16 \%$ of the African continents' countries, highlighting the opportunities to investigate and address psychological phenomena in more African countries.

\section{Conclusion}

Looking back through the reviews of previous research effectively discerns the current gaps and needs for methodological improvement. Based on the results and discussion above, it is clear that reporting standards in African journals regarding the use of convenience samples are in some cases similar or even more detailed than those found in international journals. However, reporting convenience sampling methods, or participants characteristics still had low frequencies or were omitted entirely, and these practices require our reflection and attention. Therefore, it is recommended that this study and the reporting categories serve as a basis for the included journals to start providing reasonable requirements for sampling method sections and participant descriptors in their manuscripts. Samples in psychology tend to consist of WEIRD participants, and Rad et al. (2018) encourage editors to see the research using nonWEIRD samples as contributors to novel research and integral importance. Therefore, it is encouraged that research providing samples from different backgrounds, such as Africa, be transparent and methodologically sound.

\section{Acknowledgements}

Prof Leon T. de Beer from the WorkWell Research Unit, NorthWest University, Potchefstroom acted as the second reviewer for the current study and is acknowledged in the manuscript.

\section{Competing interests}

The author declares that they have no financial or personal relationships that may have inappropriately influenced them in writing this article.

\section{Author's contributions}

S.E.S. is the sole author of this article.

\section{Funding information}

This research received no specific grant from any funding agency in the public, commercial or not-for-profit sectors.

\section{Data availability}

The data that support the results of this study are available from the author, S.E.S. upon reasonable request.

\section{Disclaimer}

The views and opinions expressed in this article are those of the author and do not necessarily reflect the official policy or position of any affiliated agency of the author.

\section{References}

Acharya, A.S., Prakash, A., Pikee, S., \& Nigam, A. (2013). Sampling: Why and how of it? Indian Journal of Medical Specialities, 42(2), 330-333. https://doi.org/10.7713/ ijms.2013.0032

Aguinis, H., \& Solarino, A.M. (2019). Transparency and replicability in qualitative research: The case of interviews with elite informants. Strategic Management Journal, 4O(8), 1291-1315. https://doi.org/10.1002/smj.3015

Andrade, C. (2020). The inconvenient truth about convenience and purposive samples. Indian Journal of Psychology Medicine, 43(1), 86-88. https://doi.org/10.1177/0253717620977000

Anyaegbunam, E.N., \& Anazonwu, C.O. (2018). Self-motivated behaviour: Its influence on intergroup contact for intergroup harmony. Journal of Psychology in Africa, 28(3), 175-181. https://doi.org/10.1080/14330237.2018.1475462

AOSIS. (2020). South African Journal of Industrial Psychology: Submission guidelines. Retrieved from https://sajip.co.za/index.php/sajip/pages/view/submissionguidelines\#part_1

Arendse, D.E., \& Maree, D. (2019). Exploring the factors of the English Comprehension Test. South African Journal of Psychology, 49(3), 376-390. https://doi.org/10.1177/0081246318805268

Ashraf, R., \& Merunka, D. (2017). The use and misuse of student samples: An empirical investigation of European marketing research. Journal of Consumer Behaviour, 16(4), 295-308. https://doi.org/10.1002/cb.1590

Barratt, M.J., Ferris, J.A., \& Lenton, S. (2015). Hidden populations, online purposive sampling, and external validity: Taking off the blindfold. Field Methods, 27(1) 3-21. https://doi.org/10.1177/1525822X14526838

Braun, V., \& Clark, V. (2012). Thematic analysis. In H. Cooper (Ed.), APA handbook of research in psychology: Vol 2. Research designs (pp. 57-71). Washington, DC: American Psychological Association. https://doi.org/10.1037/13620-004

Buckley, J., Brown, M., Thomson, S., Olsen, W., \& Carter, J. (2015). Embedding quantitative skills into the Social Science curriculum: Case studies from Manchester. International Journal of Social Research Methodology, 18(5), 495-510. https://doi.org/10.1080/13645579.2015.1062624

Cleary, M., Horsfall, J., \& Hayter, M. (2014). Data collection and sampling in qualitative research: Does size matter? Journal of Advanced Nursing, 70(3), 473-475. https://doi.org/10.1111/jan.12163

Coetzee, M., \& Van Zyl, L.E. (2013). Advancing research in industrial and organisational psychology - A brief overview of 2013. South African Journal of Industrial Psychology, 39(1), 1-4. https://doi.org/10.4102/sajip.v39i1.1174

Coetzee, M., \& Van Zyl, L.E. (2014). A review of a decade's scholarly publications (2004-2013) in the South African Journal of Industrial Psychology. South African Journal of Industrial Psychology, 40(1), 1-16. https://doi.org/10.4102/sajip. v40i1.1227

Dankaert, E.S., Guse, T., \& Van Zyl, C.J. (2019). Psychometric properties of the motivation for solitude scale-short form in a sample of South African adolescents. South African Journal of Psychology, 49(1), 14-26. https://doi.org/10.1177/0081246317744391

Etikan, I., Musa, S.A., \& Alkassim, R.S. (2016). Comparison of convenience sampling and purposive sampling. American Journal of Theoretical and Applied Statistics, 5(1), 1-4. https://doi.org/10.11648/j.ajtas.20160501.11

Fisher, G.G., \& Sandell, K. (2015). Sampling in industrial-organizational psychology research: Now what? Industrial and Organisational Psychology, 8(2), 232-237. https:/doi.org/10.1017/iop.2015.31

Fonseca, M. (2013). Most common reasons for journal rejections. Retrieved from https://www.editage.com/insights/most-common-reasons-for-journalrejection?refer=scroll-to-1-article\&refer-type=article

Gani, K., Potgieter, I., \& Coetzee, M. (2020). Dispositions of agency as explanatory mechanisms of employees' satisfaction with retention practices. Journal of Psychology in Africa, 30(2), 143-150. https://doi.org/10.1080/14330237.2020.17 44278

Geils, C., \& Edwards, S.D. (2018). Extended family constellations workshop efficacy on intuition measure and experience. Journal of Psychology in Africa, 28(3), 224-228. https://doi.org/10.1080/14330237.2018.1475527

Gentles, S.J., Charles, C., Nicholas, D.B., Ploeg, J., \& McKibbon, K.A. (2016). Reviewing the research methods literature: Principles and strategies illustrated by a systematic overview of sampling in qualitative research. Systematic Reviews, 5(1), 172. https:/doi.org/10.1186/s13643-016-0343-0

Grant, M.J., \& Booth, A. (2009). A typology of reviews: An analysis of 14 review types and associated methodologies. Health Information \& Libraries Journal, 26(2), 91-108. https://doi.org/10.1111/j.1471-1842.2009.00848.x 
Hanges, P.J., \& Wang, M. (2012). Seeking the Holy Grail in organisational science: Uncovering causality through research design. In S. Kozlowski (Ed.), The Oxford handbook of organisational psychology (pp. 79-116). Oxford: Oxford Handbooks Online.

Henn, C., \& Morgan, B. (2019). Differential item functioning of the CESDR-R and GAD7 in African and white working adults. South African Journal of Industrial Psychology, 45(0), 1-10. https://doi.org/10.4102/sajip.v45i0.1663

Henrich, J., Heine, S.J., \& Norenzayan, A. (2010). The weirdest people in the world? Behavioral and Brain Sciences, 33(2-3), 61-83. https://doi.org/10.1017/ S0140525'0999152X

Hesse-Biber, S. (2015). The problems and prospects in the teaching of mixed methods research. International Journal of Social Research Methodology, 18(5), 463-477. https://doi.org/10.1080/13645579.2015.1062622

Hlatshwayo, G.M., Muthukrishna, N., \& Martin, M. (2018). 'Inhliziyo ekhombisa uthando': Exploring children's conceptions of spirituality. Journal of Psychology in Africa, 28(1), 56-61. https://doi.org/10.1080/14330237.2018.1426809

Hultsch, D.F., MacDonald, S.W., Hunter, M.A., Maitland, S.B., \& Dixon, R.A. (2002) Sampling and generalisability in developmental research: Comparison of random and convenience samples of older adults. International Journal of Behaviora Development, 26(4), 345-359. https://doi.org/10.1080\%2F01650250143000247

Idang, G.E. (2015). African culture and values. Phronimon, 16(2), 97-111. Retrieved from http://www.scielo.org.za/scielo.php?script=sci_arttext\&pid $=$ S1561-40182015000200006

Jager, J., Putnick, D.L., \& Bornstein, M.H. (2017). More than just convenient: The scientific merits of homogenous convenience samples. Monographs of the Society for Research in Child Development, 82(2), 13-30. https://doi.org/10.1111/ mono.12296

Jimenez-Buedo, M., \& Miller, L.M. (2010). Why a trade-off? The relationship between the external and internal validity of experiments. Theoria. Revista de Teoría, Historia y Fundamentos de la Ciencia, 25(3), 301-321. Retrieved from https://www-pdcnetorg.nwulib.nwu.ac.za/theoria/content/theoria_2010 0025000303010321

Johnston, A., Kelly, S.E., Hsieh, S.C., Skidmore, B., \& Wells, G.A. (2019). Systematic reviews of clinical practice guidelines: A methodological guide. Journal of Clinical Epidemiology, 108, 64-72. https://doi.org/10.1016/j.jclinepi.2018.11.030

Kagee, A., Bantjes, J., Saal, W., \& Sefatsa, M. (2019). Utility of the posttraumatic stress scale-self-report version in screening for posttraumatic stress disorder among persons seeking HIV testing. South African Journal of Psychology, 49(1), 136-147. https://doi.org/10.1177/0081246318779191

Kakinami, L., \& Conner, K.R. (2010). Sampling strategies for addiction research. In G. Miller, J. Strang, \& P.M. Miller (Eds.), Addiction research methods (pp. 27-42) Malaysia: Wiley-Blackwell.

Keyser, N., \& Cecile Duvenhage, C. (2019). Construct validity of a financial literacy instrument. Journal of Psychology in Africa, 29(5), 460-465. https://doi.org/ 10.1080/14330237.2019.1667151

Landers, R.N., \& Behrend, T.S. (2015). An inconvenient truth: Arbitrary distinctions between organisational, mechanical turk, and other convenience samples. Industrial and Organisational Psychology, 8(2), 142-164. https://doi.org/10.1017/ iop.2015.13

Lucas, S.R. (2014). Beyond the existence proof: Ontological conditions, epistemological implications, and in-depth interview research. Quality \& Quantity, 48(1), 387-408. http://doi.org/10.1007/s11135-012-9775-3

Maree, K., \& Pietersen, J. (2016). Sampling. In K. Maree (Ed.), First steps in research (2nd edn., pp. 192-202). Pretoria: Van Schaik.

Maximo, N., Stander, M.W., \& Coxen, L. (2019). Authentic leadership and work engagement: The indirect effects of psychological safety and trust in supervisors. South African Journal of Industrial Psychology, 45(0), 1-11. https://doi. org/10.4102/sajip.v45i0.1612

McEwan, B. (2020). Sampling and validity. Annals of the International Communication Association, 44(3), 235-247. https://doi.org/10.1080/23808985.2020.1792793

Medin, D., Ojalehto, B., Marin, A., \& Bang, M. (2017). Systems of (non-) diversity. Nature Human Behaviour, 1(5), 0088. https://doi.org/10.1038/s41562-017-0088

Mesoudi, A. (2011). Evolutionary psychology meets cultural psychology: Review of evolution, culture and the human mind (2009). Journal of Evolutionary Psychology, 9(1), 83-87. https://doi.org/10.1556/JEP.9.2011.17.1

Mngomezulu, S. (2019). Delayed disclosure of disability related needs: Experiences of 'at-risk' students in a South African university. Journal of Psychology in Africa, 29(3), 270-274. https://doi.org/10.1080/14330237.2019.1622321

Morton, N., Hill, C., Meiring, D., \& De Beer, L.T. (2019). Investigating the factor structure of the South African Personality Inventory-English version. South African Journal of Industrial Psychology, 45(0), a1556. https://doi.org/10.4102/sajip. v45i0.1556

Ndungu, J.W., Ndetei, D.M., Cronje, J., \& Van Rooyen, K. (2018). Attribution style and post-traumatic stress severity in the Central Region of Kenya: Influences of dwelling location. Journal of Psychology in Africa, 28(5), 355-359. https://doi.org $/ 10.1080 / 14330237.2018 .1523333$

Nielsen, M., Haun, D., Kärtner, J., \& Legare, C.H. (2017). The persistent sampling bias in developmental psychology: A call to action. Journal of Experimental Child Psychology, 162, 31-38. https://doi.org/10.1016/j.jecp.2017.04.017

Ntinda, K., \& Dlamini, P.S. (2019). Educator self-perceived life skills education implementation practices: An exploratory study. Journal of Psychology in Africa, 29(5), 520-526. https://doi.org/10.1080/14330237.2019.1678852

O’Neil, S., \& Koekemoer, E. (2016). Two decades of qualitative research in psychology, industrial and organisational psychology and human resource management within South Africa: A critical review. SA Journal of Industrial Psychology, 42(1), 1-16. https://doi.org/10.4102/sajip.v42i1.1350
Open Science Collaboration. (2015). Estimating the reproducibility of psychological science. Science, 349(6251), 943-952. https://doi.org/10.1126/science.aac4716

Osei-Tutu, A., Dzokoto, V.A., Hanke, K., Adams, G., \& Belgrave, F.Z. (2018). Conceptions of love in Ghana: An exploration among Ghanaian Christians. Journal of Psychology in Africa, 28(2), 83-88. https://doi.org/10.1080/14330237.2018.1454576

Palinkas, L.A., Horwitz, S.M., Green, C.A., \& Wisdom, J.P. (2013). Purposeful sampling for qualitative data collection and analysis in mixed method implementation research. Administration and Policy in Mental Health and Mental Health Services Research, 42(2), 533-544. https://doi.org/10.1007/s10488-013-0528-y

Patton, M.Q. (2002). Qualitative research and evaluation methods. Washington, DC: Sage Publications.

Pietersen, C. (2018). Research trends in the South African journal of human resource management. South African Journal of Human Resource Management, 16(0), a825. https://doi.org/10.4102/sajhrm.v16i0.825

Pollet, T.V., \& Saxton, T. (2019). How diverse are the samples used in the journals 'evolution \& human behavior' and 'evolutionary psychology'? Evolutionary Psychological Science, 5(3), 357-368. https://doi.org/10.1007/s40806-01900192-2

Potgieter, I.L., \& Ferreira, N. (2018). Personality preference facets and self-regulatory employability of human resource professionals. South African Journal of Psychology, 48(1), 142-154. https://doi.org/10.1177/0081246316685934

Rad, M.S., Martingano, A.J., \& Ginges, J. (2018). Toward a psychology of Homo sapiens: Making psychological science more representative of the human population. Proceedings of the National Academy of Sciences, 115(45), 11401-11405. https://doi.org/10.1073/pnas.1721165115

Rawat, S., \& Menna, S. (2014). Publish or perish: Where are we heading? Journal of Research in Mecial Science, 19(2), 87-89. Retrieved from https://www.ncbi.nlm. nih.gov/pmc/articles/PMC3999612/\#ref2

Redelinghuys, K., Rothmann, S., \& Botha, E. (2019). Workplace flourishing: Measurement, antecedents and outcomes. South African Journal of Industrial Psychology, 45(0), 1-11. https://doi.org/10.4102/sajip.v45i0.1549

Renard, M., \& Snelgar, R.J. (2018). Can non-profit employees' internal desires to work be quantified? Validating the Intrinsic Work Motivation Scale. South African Journal of Psychology, 48(1), 48-60. https://doi.org/10.1177\%2F0081246317704125

Robinson, O.C. (2014). Sampling in interview-based qualitative research: A theoretical and practical guide. Qualitative Research in Psychology, 11(1), 25-41. https://doi.org/10.1080/14780887.2013.801543

Rozin, P. (2001) Social psychology and science: Some lessons from Solomon Asch. Personality Social Psychology Review, 5(1), 2-14. https://doi.org/10.1207\%2FS15 327957PSPR0501_1

Rynes, S.L. (2012). The research-practice gap in industrial-organisational psychology and related fields: Challenges and potential solutions. In S.W.J. Kozlowski (Ed.), Oxford handbook of organisational psychology (pp. 409-452). Oxford: Oxford University Press.

SAGE Publishing. (2021). Manuscript submission quidelines. Retrieved from https://us.sagepub.com/en-us/nam/manuscript-submission-guidelines\#Preparin gYourManuscript

Scholtz, S.E., De Klerk, W. \& De Beer, L.T. (2020). The use of research methods in psychological research: A systematised review. Frontiers in Research Metrics and Analytics, 5(1), 1-17. https://doi.org/10.3389/frma.2020.00001

Schreuder, D., \& Coetzee, M. (2010). An overview of industrial and organisational psychology research in South Africa: A preliminary study. SA Journal of Industrial Psychology, 36(1), 1-11. https://doi.org/10.4102/sajip.v36i1.903

Scott Jones, J., \& Goldring, J.E. (2015). 'I'm not a quants person'; key strategies in building competence and confidence in staff who teach quantitative research methods. International Journal of Social Research Methodology, 18(5), 479-494. https://doi.org/10.1080/13645579.2015.1062623

Shen, W., Kiger, T.B., Davies, S.E., Rasch, R.L., Simon, K.M., \& Ones, D.S. (2011). Samples in applied psychology: Over a decade of research in review. Journal of Applied Psychology, 96(5), 1055-1064. https://doi.org/10.1037/a0023322

Shoko, E. (2019). Peaceful waters: Community action in sustainable scarce resource management in a rural Zimbabwean setting. Journal of Psychology in Africa, 29(2), 167-171. https://doi.org/10.1080/14330237.2019.1594636

Simons, D., Yuichi, S., \& Lindsay, D. (2017). Constraints on generality (COG): A proposed addition to all empirical papers. Retrieved from https://osf.io/ preprints/psyarxiv/w9e3r

Snyder, H. (2019). Literature review as a research methodology: An overview and guidelines. Journal of Business Research, 104, 333-339. https://doi.org/10.1016/j. jbusres.2019.07.039

Staetsky, L.D. (2019). Can convenience samples be trusted? Lessons from the survey of Jews in Europe, 2012. Contemporary Jewry, 39(1), 115-153. https://doi.org/ 10.1007/s12397-019-09280-8

Steckler, A., \& McLeroy, K.R. (2008). The importance of external validity. American Journal of Public Health, 98(1), 9-10. https://doi.org/10.2105/AJPH.2007.126847

Stroebe, W., Gadenne, V., \& Nijstad, B.A. (2018). Do our psychological laws apply only to college students?: External validity revisted. Basic and Applied Social Psychology, 40(6), 384-395. https://doi.org/10.1080/01973533.2018.1513362

Tasamba, J. (2019). African countries push for higher literacy. Retrieved from https:// www.aa.com.tr/en/africa/african-countries-push-for-higher-literacy/1618099

Taylor \& Francis Online. (2021). Instructions for authors. Retrieved from https://www. tandfonline.com/action/authorSubmission?show=instructions\&journalCode=rpia20

Trafimow, D. (2018). An a priori solution to the replication crisis. Philosophical Psychology, 31(8), 1188-1214. https://doi.org/10.1080/09515089.2018.1490707 
United Nations. (2019). Population facts. Retrieved from https://www.un.org/ en/development/desa/population/publications/pdf/popfacts/PopFacts 2019-6.pdf

Van Leeuwen, J.M., Miller, L., Zamir, M., Grundy, R., Amanya, J., Chen, C., \& Feinberg, M. (2018). Community reintegrating former child soldiers in Northern Uganda: A qualitative study on the road to recovery. Journal of Psychology in Africa, 28(2), 105-109. https://doi.org/10.1080/14330237.2018.1454580

Vasileiou, K., Barnett, J., Thorpe, S., \& Young, T. (2018). Characterising and justifying sample size sufficiency in interview-based studies: Systematic analysis of qualitative health research over a 15-year period. BMC Medical Research Methodology, 18(1), 148. https://doi.org/10.1186/s12874-018-0594-7

Visser, D., \& Van Staden, F. (1990). Analysis of sample selection, sample composition and research design: A review of the past decade's contributions to the South African Journal of Psychology. South African Journal of Psychology, 20(2) 111-119. https://doi.org/10.1177\%2F008124639002000207
Waglay, M., Becker, J.R., \& du Plessis, M. (2020). The role of emotional intelligence and autonomy in transformational leadership: A leader member exchange perspective. South African Journal of Industrial Psychology, 46(1), 12. https://doi.org/10.4102/ sajip.v46i0.1762

Web of Science Group. (2020). Master journal list. Retrieved from https://mjl. clarivate.com/search-results

Westfall, J., Judd, C.M., \& Kenny, D.A. (2015). Replicating studies in which samples of participants respond to samples of stimuli. Perspectives on Psychological Science, 10(3), 390-399. https://doi.org/10.1177/1745691614564879

Wienclaw, R.A. (2019). Salem press encyclopedia. Retrieved from https://eds-aebscohost-com.nwulib.nwu.ac.za/eds/detail/detail?vid=1\&sid=614866f5-65a9 420e-ae7d-8e493c8583d6\%40sdc-v-sessmgr01\&bdata=JnNpdGU9ZWRzLWxp $\mathrm{mU} \% 3 \mathrm{~d} \# \mathrm{AN}=89185687 \& \mathrm{db}=\mathrm{er}$

Zhao, K. (2020). Sample representation in the social sciences. Synthese, 1-19. https://doi.org/10.1007/s11229-020-02621-3

Appendix 1 starts on the next page $\rightarrow$ 


\section{Appendix 1}

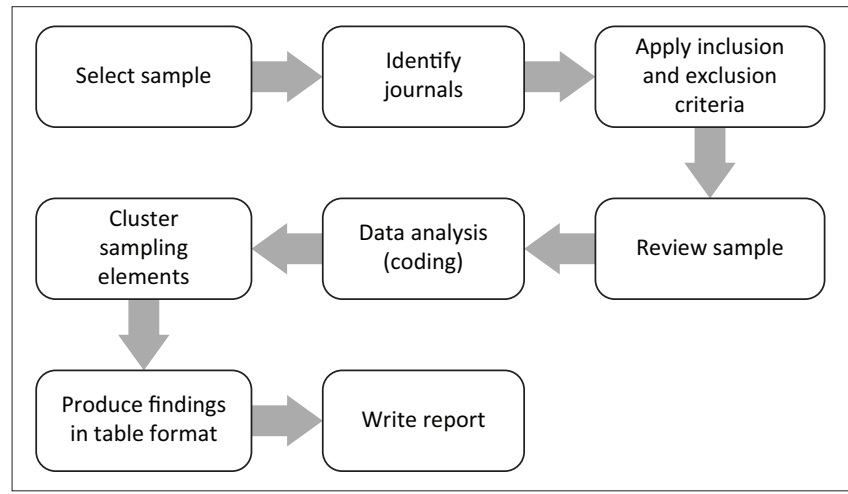

Source: Adapted from Scholtz, S.E., De Klerk, W., \& De Beer, L.T. (2020). The use of research methods in psychological research: A systematised review. Frontiers in Research Metrics and Analytics, 5(1), 1-17. https://doi.org/10.3389/frma.2020.00001

FIGURE 1-A1: Systematised review design process. 